\title{
Successful Percutaneous Revascularization in a Patient with a Chronic Totally Occluded Renal Artery in an Atrophied Kidney
}

\author{
Yoshiki Nagata, Yoko Taniguchi, Kazuo Usuda, Masahiko Kawabata and Hiroyuki Iida
}

\begin{abstract}
A 57-year-old man presented with renovascular hypertension with chronic kidney disease. 16-Multidetector row computed tomography (MDCT) showed that the left renal artery was totally occluded and the left kidney was atrophied. The left atrophied kidney was hormonally active despite the desolation of glomerular filtration function. Percutaneous renal revascularization was successful for stenting this lesion. The renin activity in the left renal vein was decreased immediately after the procedure. He remained healthy with adequate blood pressure for three years. In this case, MDCT and renal vein renin measurement provided useful information for the decision to perform percutaneous renal revascularization.
\end{abstract}

Key words: atherosclerotic renovascular disease, computed tomography, percutaneous renal revascularization, stent

(Inter Med 49: 215-219, 2010)

(DOI: 10.2169/internalmedicine.49.2629)

\section{Introduction}

Percutaneous renal revascularization with stenting is generally effective for improving hypertension, and stabilizing renal failure in a substantial percentage of patients, and in eliminating recurrent cardiac events in patients with atherosclerotic renal artery stenosis $(1,2)$. However, chronic total occlusion of a renal artery supplying a small atrophied kidney had not been considered an appropriate target for intervention because renal artery revascularization would not be expected to improve hypertension and renal function (3).

The present case indicates that an atrophied kidney can be hormonally active, and therefore contribute to significant hypertension. Furthermore, the occlusion of the ostial portion of the renal artery was a complex lesion for percutaneous renal revascularization. This report demonstrates that the recanalization of a chronically occluded renal artery may result in the restoration of the renal function.

\section{Case Report}

The patient was a 57-year-old man with a past history of dyslipidemia, arteriosclerosis obliterans and tobacco use. In March 2006, he began to feel general malaise and headache. He consulted a neighborhood doctor. He was found to have a blood pressure of $200 / 120 \mathrm{mmHg}$, positive proteinuria and a serum creatinine level of $1.2 \mathrm{mg} / \mathrm{dL}$. He started taking a calcium channel antagonist (azelnidipine $16 \mathrm{mg}$ once a day). However, his blood pressure was not sufficiently controlled. He took four antihypertensive drugs (enalapril $5 \mathrm{mg}$, nifedipine CR $40 \mathrm{mg}$, labetalol $200 \mathrm{mg}$ and indapamide 1 mg daily).

Despite this therapy, his blood pressure remained in the range of $150 / 100 \mathrm{mmHg}$ and his renal function worsened (serum creatinine $1.5 \mathrm{mg} / \mathrm{dL}$ ). He was admitted to the hospital for hypertension refractory to antihypertensive drugs. His blood pressure was $142 / 80 \mathrm{mmHg}$ on admission. His laboratory data showed total cholesterol $229 \mathrm{mg} / \mathrm{dL}$, triglyceride $220 \mathrm{mg} / \mathrm{dL}$ and $\mathrm{HbA1c} 4.8 \%$. His ocular fundus showed arteriolosclerosis (Scheie H3S2). Proteinuria was $2.1 \mathrm{~g} /$ day 
A

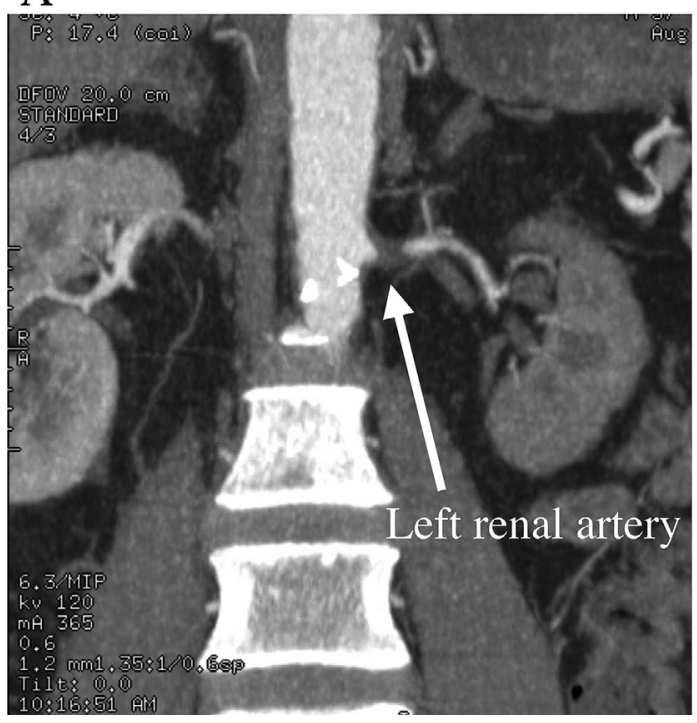

B

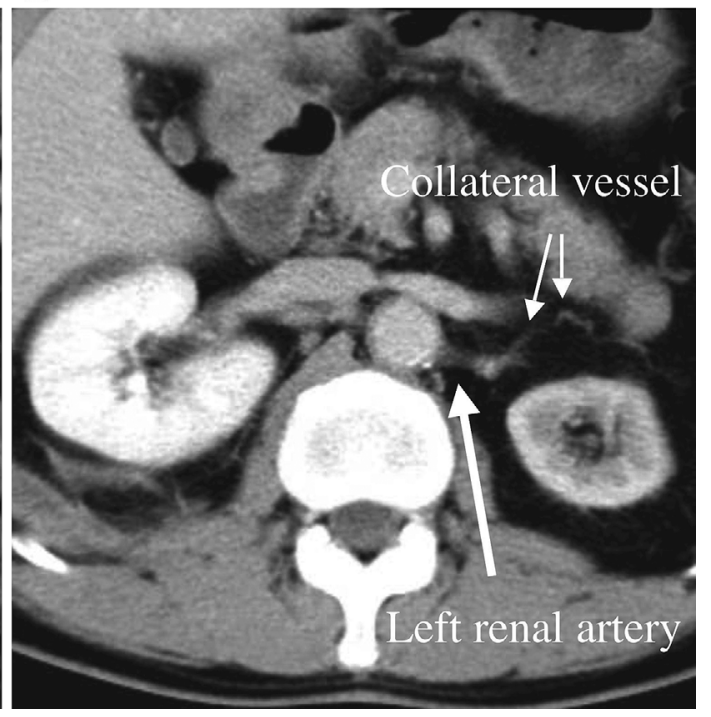

Figure 1. 16-Multi-detector row computed tomography (MDCT). MDCT shows total occlusion of the left renal artery (black arrow). The left renal artery was located lower than the right renal artery and the upper of the third vertebrae lumbales (A). The abdominal aorta and left renal artery angulations were $25^{\circ}(\mathrm{B})$. A small collateral vessel supplying the left kidney may have been a branch of the superior mesenteric artery (white arrow).

and creatinine clearance was $53.4 \mathrm{~mL} / \mathrm{min}$. Plasma renin activity was $20 \mathrm{ng} / \mathrm{mL} / \mathrm{hr}$ and plasma aldosterone concentration was $249 \mathrm{pg} / \mathrm{mL}$. 16-Multi-detector row computed tomography (MDCT) was performed to determine the severity of the renal artery disease and renal size. The left renal artery was found to be occluded (lesion length $1.5 \mathrm{~cm}$ ) and the left kidney size was $6.5 \times 4.9 \times 4.3 \mathrm{~cm}$ (Figs. 1A, 1B). A small collateral vessel passing into the left kidney was possibly a branch artery of the superior mesenteric artery. The right renal artery had moderate stenosis, and the right kidney size was $10 \times 6.7 \times 5.8 \mathrm{~cm}$. To determine the differential functional status of the left kidney, renal radionuclide scintigraphy with ${ }^{99} \mathrm{~m}$-Technetium was used to calculate the glomerular filtration rate (GFR). The GFR was $5.1 \mathrm{~mL} / \mathrm{min}$ of left kidney and $37.1 \mathrm{~mL} / \mathrm{min}$ of right kidney. The renin activity in the renal vein was increased, especially in the left renal vein (left renal vein $101.2 \mathrm{ng} / \mathrm{mL} / \mathrm{hr}$, right renal vein $16.4 \mathrm{ng} / \mathrm{mL} / \mathrm{hr}$, and inferior vena cava $19.0 \mathrm{ng} / \mathrm{mL} / \mathrm{hr}$ ). These studies confirmed that the left kidney was hormonally active despite a poor glomerular filtration function.

Due to the failure to medically manage the patient's hypertension and chronic kidney disease, the cardiovascular surgery and nephrology departments were consulted and they determined that left renal artery revascularization should be performed. Written informed consent was obtained from the patient and his family after they were informed of the treatment and complications.

Abdominal aortography showed a total occlusion of the ostium of the renal artery (Fig. 2A). However, it was impossible to confirm the ostial part and distal part of left renal artery. The position of the left renal artery was determined using MDCT. The left renal artery was located at the lower portion of the right renal artery and the upper portion of the third vertebrae lumbales (Fig. 1A). The abdominal aorta and left renal artery angulations were $25^{\circ}$ (Fig. 1B). This indicated that this part was the ostial part of the left renal artery. An image intensifier was angulated into a left anterior oblique view at $25^{\circ}$. An 8 Fr RDC(I) guiding catheter was positioned at the ostial part of the left renal artery using the aorta no touch technique (Fig. 2B). The total occluded lesion was crossed with a 0.018 inch Neo's treasure guidewire (Asahi Intec Corp., Tokyo, Japan). However, the microcatheter did not pass through (Fig. 2C). A 0.014 inch Neo's soft guidewire (Asahi Intec Corp.) could cross into the distal true channel using the parallel wire technique and predilation with a $1.5 \mathrm{~mm}$ balloon (Fig. 2D). Further dilation was performed with a $4 \mathrm{~mm}$ balloon at $7 \mathrm{~atm}$. A Palmatz $6.0 \times 18$ $\mathrm{mm}$ stent (Cordis Corp., USA) was positioned at the ostial lesion ensuring that the proximal marker of the stent was exactly protruding proximally in the renal artery (Fig. 2E). The stent deployed at 12 atm without complications and showed the restoration of renal flow (Fig. 2F). The left renal vein renin activity decreased from 99 to $11 \mathrm{ng} / \mathrm{mL} / \mathrm{hr}$ immediately after the procedure. The patient's systolic blood pressure was better controlled at 120/60 $\mathrm{mmHg} 7$ days after the procedure. He was administered a single antihypertensive drug (enalapril $2.5 \mathrm{mg}$ daily). The GFR improved to 10.1 $\mathrm{mL} / \mathrm{min}$ in the left kidney and $52.8 \mathrm{~mL} / \mathrm{min}$ in the right kidney.

Renal MDCT showed a patent left renal stent two years after the index procedure (Fig. 3). The small collateral vessel into the left kidney had disappeared. The size of the kidney had not changed (left kidney size $6.5 \times 5.1 \times 4.4 \mathrm{~cm}$, right kidney size $11 \times 6.2 \times 5.9 \mathrm{~cm})$. The patient took enarapril 2.5 
A

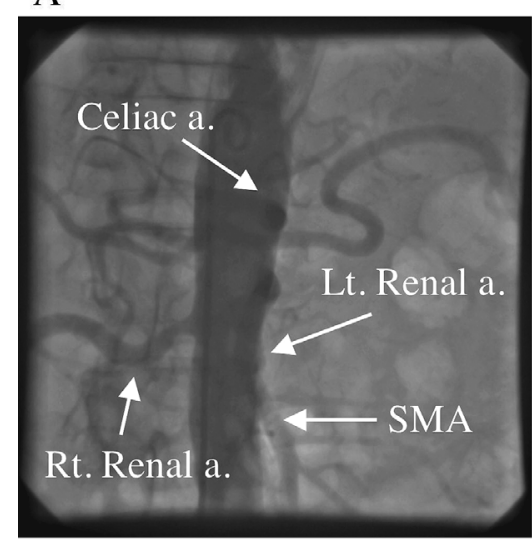

$\mathrm{D}$

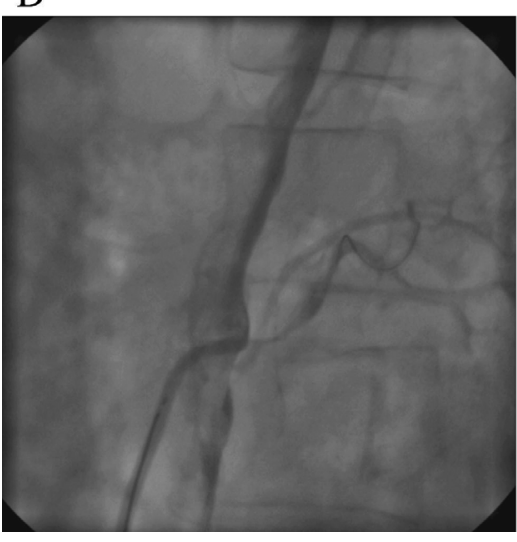

B

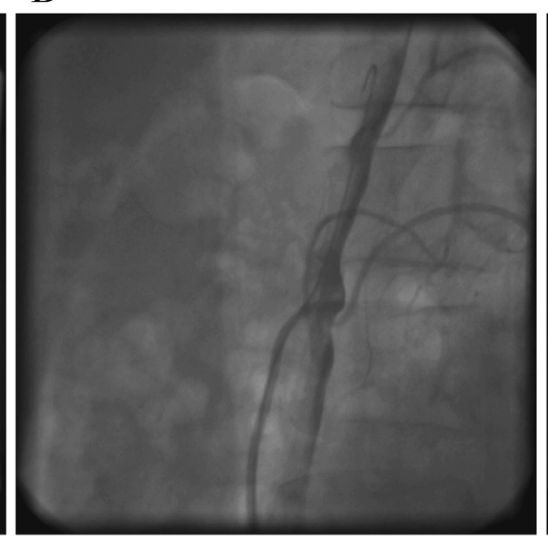

$\mathrm{E}$

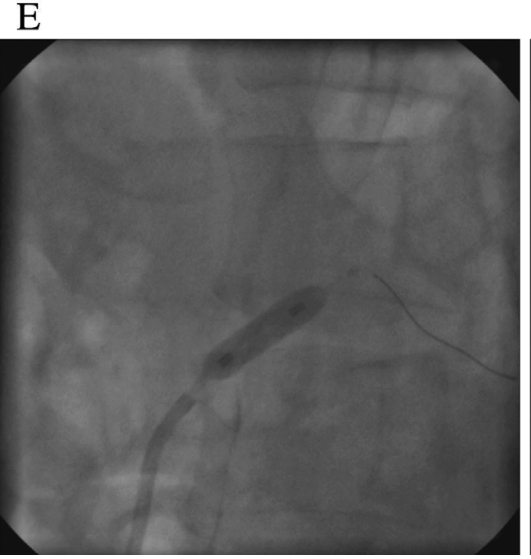

$\mathrm{C}$

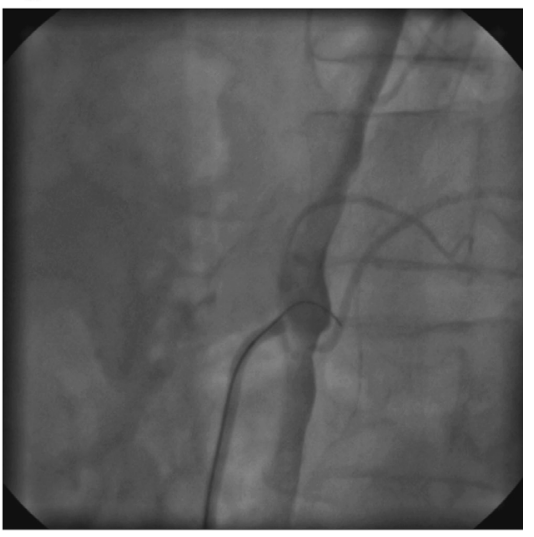

$\mathrm{F}$

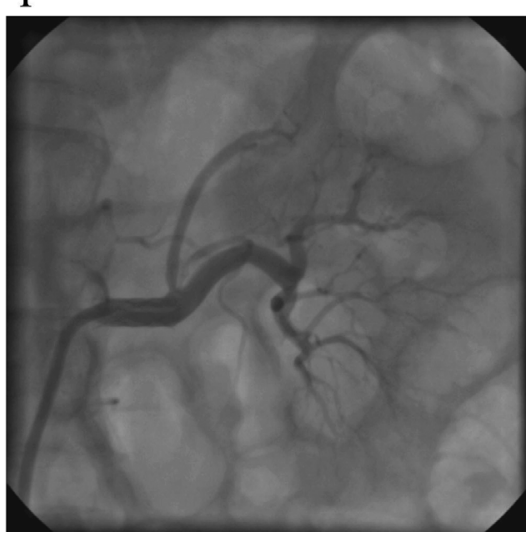

Figure 2. Percutaneous renal revascularization. Abdominal aortography showed total occlusion of the ostium of the left renal artery (A). An image intensifier was angulated to a left anterior oblique view of $25^{\circ}$. An $8 \mathrm{Fr}$ RDC(I) guiding catheter was positioned at the left renal artery ostial part using the aorta no touch technique $(B)$. The total occluded lesion was crossed with a 0.018 inch Neo's treasure guidewire. However, the microcatheter was not passed (C). Therefore, a 0.014 inch Neo's soft guidewire was passed into the distal true channel using the parallel wire technique and predilation with a $1.5 \mathrm{~mm}$ balloon (D). Further dilation was performed with a $4 \mathrm{~mm}$ balloon at 7 atm. A Palmatz $6.0 \times 18 \mathrm{~mm}$ stent was positioned at the ostial lesion ensuring that the proximal marker of the stent was protruding precisely proximally in the renal artery (E). The stent deployed at 12 atm without complications and showed the restoration of renal flow (F). SMA: superior mesenteric artery

$\mathrm{mg}$, aspirine $100 \mathrm{mg}$ and ticropidine $200 \mathrm{mg}$ daily after discharge. Figure 4 shows the clinical course of this patient. His plasma renin activity ranged from 2.2 to $2.6 \mathrm{ng} / \mathrm{mL} / \mathrm{hr}$ and the plasma aldosterone concentration ranged from 6.2 to $7.9 \mathrm{pg} / \mathrm{mL}$. His renal function was stabilized (serum creatinine ranged from 1.3 to $1.5 \mathrm{mg} / \mathrm{dL}$ ), and proteinuria had disappeared. The patient is presently doing well with sufficiently controlled blood pressure at 3 years after the percutaneous renal revascularization (ranging from 122/80 to 135/ $97 \mathrm{mmHg}$ ).

\section{Discussion}

Renal artery stenting has emerged as a safe therapy for both unilateral and bilateral renal artery stenosis and is indicated for refractory hypertension, especially when it is associated with congestive heart failure $(2,4)$. Numerous studies have demonstrated low restenosis rates and have shown some improvement in the blood pressure control (2-4) as well as improvement or stabilization of creatinine clearance (4-6), while risks have included cholesterol embolization, progression of renal disease and bleeding (2, 4). However, the benefits and long patency after renal artery stenting have not yet been determined for chronic total occlusion of a renal artery supplying a small atrophied kidney. Alhadad et al reported sustained beneficial effects on blood pressure over a long (mean 2.6 years) follow-up after percutaneous renal revascularization of renal artery occlusion without atrophied kidney (7). In their article, it was reported that revascularization was not attempted in patients with atrophied kidney (renal size $<7 \mathrm{~cm}$ ). Wykrzykowska et al reported renal artery stenting for a total occlusion in a patient without atrophied kidney $(8.4 \mathrm{~cm}$ of affected kidney size) that maintained a patent renal stent for 5 months after the procedure (8). The current case showed a longer period of a patent renal stent and improvement of hypertension over three 


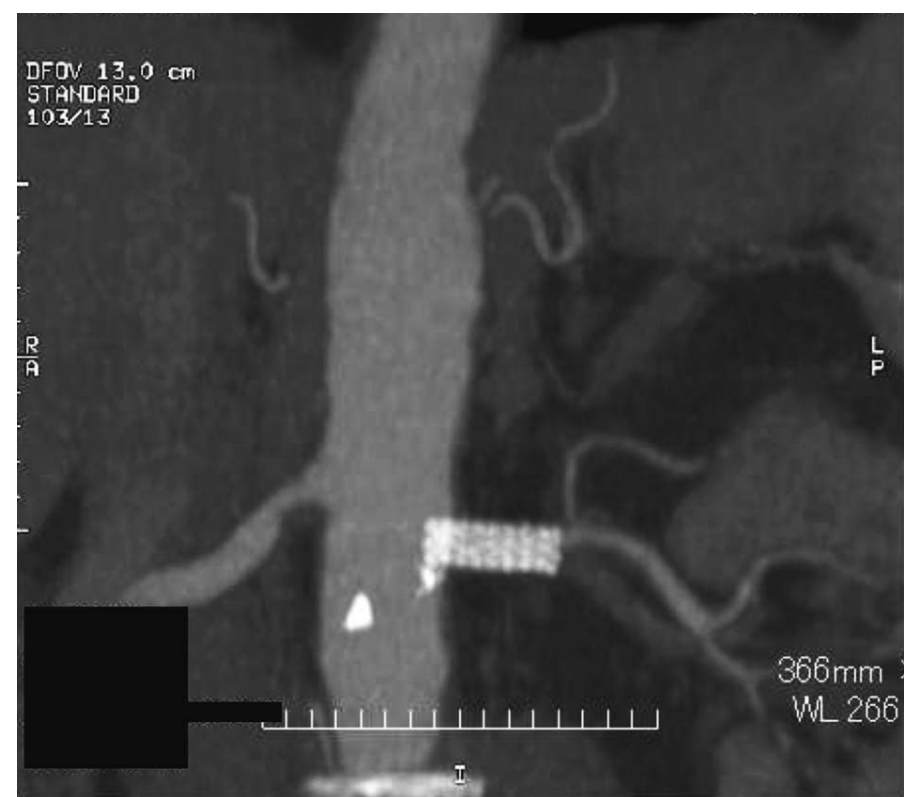

Figure 3. 16-Multi-detector row computed tomography (MDCT) after percutaneous renal revascularization. Renal MDCT showed a patent left renal stent after 2 years.

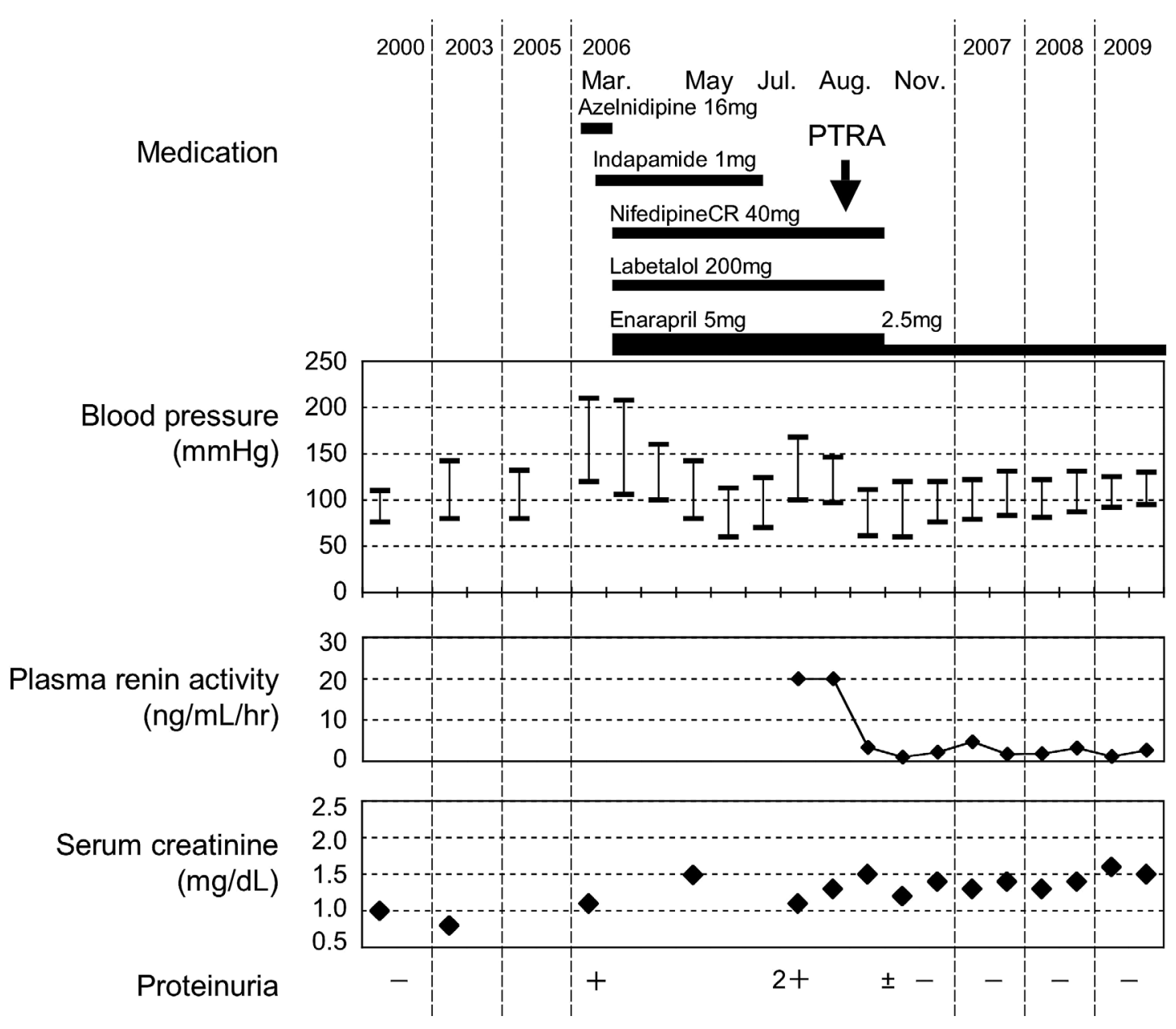

Figure 4. The clinical course of the patient. Atherosclerotic renovascular disease showed chronic kidney disease and refractory hypertension. He took four antihypertensive drugs. After percutaneous renal revascularization (PTRA), his renal function was stabilized and the proteinuria had disappeared. He was administered a single antihypertensive drug (enalapril $2.5 \mathrm{mg}$ daily). The patient was presently doing well with a sufficiently controlled blood pressure at the 3-year follow-up. 
years. Therefore, this case had the most atrophied kidney of the previously reported cases.

Commonly, medical therapy is favored over renal revascularization in patients with a renal length of less than $7 \mathrm{~cm}$, proteinuria over $1 \mathrm{~g} / \mathrm{day}$, and severe diffuse intrarenal vascular disease, all of which provide evidence of underlying advanced nephropathy (1). The present case showed an atrophied kidney, proteinuria and a chronically total occluded renal artery. However, the renin activity from the renal vein of the atrophied kidney was highly increased. This patient's hypertension was thought to be associated with the renin activity of the left atrophied kidney. Renal vein renin measurements can be used as a predictive test for revascularization or surgically correctable renal disease when the ischemic and atrophied kidney has a significantly higher venous plasma renin activity than the normal kidney (9). Stenting of the chronic ostial left renal artery occlusion appears to have allowed for better control of blood pressure and allowed the patient to decrease the number of antihypertensive drugs necessary to maintain control of his blood pressure.

To date there have been few reports of percutaneous revascularization of a chronic ostial occlusion in the renal artery $(7,8)$. This is because it is difficult to find the ostial portion of the renal artery and to acquire stable guiding support. In the present case, surgical revascularization or a nephrectomy was effective and definite treatment. Angiography did not provide any information as to the location of the ostium of left renal artery and lesion length of the occlusion. However, percutaneous revascularization was selected, because the vascular anatomy was confirmed by MDCT. This lesion was a short occluded lesion and the interlobar artery of the left kidney maintained good vessel flow. In this procedure, MDCT facilitated the precise localization of the ostial part of the totally occluded renal artery. MDCT provided useful information about the vessel form, lesion length, calcification and the anatomy of the distal part. It is important to repeatedly review the MDCT for complete anatomical understanding of the occluded artery. Furthermore, stable guiding support was acquired using the aorta no touch technique. This technique also made it possible to avoid catheter-induced trauma, such as dissection.

Recently, MDCT has improved the spatial and temporal resolution and allowed visualization of the cardiovascular disease (10). However, renal artery stenosis sometimes complicates renal dysfunction. It was necessary to avoid contrast media exposure that would require prophylaxis against contrast-induced nephropathy (11).

\section{Conclusion}

Atherosclerotic renovascular disease showed chronic kidney disease and refractory hypertension. The atrophied kidney was hormonally active despite the desolation of glomerular filtration function. The refractory hypertension improved and renal function stabilized three years after opening a total occluded renal artery to supply a small atrophied kidney. Both renal vein renin measurements and MDCT therefore provide useful information for the selection of percutaneous renal revascularization in patients demonstrating advanced nephropathy with complex renovascular disease.

\section{Acknowledgement}

The authors wish to thank Dr. Yoshitake Satomura of Satomura Internal Medical Clinic for providing the clinical information of this patient.

\section{References}

1. Creager MA, Jones DW, Easton JD, et al. Atherosclerotic vascular disease conference, Writing group V: Medical decision making and therapy. Circulation 109: 2634-2642, 2004.

2. Rocha-Singh K, Jaff MR, Rosenfield K. Evaluation of the safety and effectiveness of renal artery stenting after unsuccessful balloon angioplasty: the ASPIRE-2 study. J Am Coll Cardiol 46: 776-783, 2005.

3. Corriere MA, Pearce JD, Edwards MS, Stafford JM, Hansen KJ. Endovascular management of atherosclerotic renovascular disease: early results following primary intervention. J Vasc Surg 48: 580587, 2008.

4. Bettmann MA, Dake MD, Hopkins LN, et al. Atherosclerotic vascular disease conference, Writing group VI: Revascularization. Circulation 109: 2643-2650, 2004.

5. Watson PS, Hadjipetrou P, Cox SV, Piemonte TC, Eisenhauer AC. Effect of renal artery stenting on renal function and size in patients with atherosclerotic renovascular disease. Circulation 102: 1671-1677, 2000.

6. Bates MC, Campbell JE, Broce M, Lavigne PS, Riley MA. Serum creatinine stabilization following renal artery stenting. Vasc Endo- vascular Surg 42: 40-46, 2008.

7. Alhadad A, Mattiasson I, Ivancev K, Gottsäter A, Lindblad B. Sustained beneficial effects on blood pressure during long time retrospective follow-up after endovascular treatment of renal artery occlusion. J Hum Hypertens 18: 739-744, 2004.

8. Wykrzykowska JJ, Williams M, Laham RJ. Stabilization of renal function, improvement in blood pressure control and pulmonary edema symptoms after opening a totally occluded renal artery. J Invasive Cardiol 20: E26-E29, 2008.

9. Alchi B, Shirasaki A, Narita I, et al. Renovascular hypertension: A unique cause of unilateral focal segmental glomerulosclerosis. Hypertens Res 29: 203-207, 2006.

10. Mitsutake R, Miura S, Tanaka T, Matsuo K, Saku K. Coronary artery aneurysm with thrombus evaluated by multi-detector row computed tomography. Intern Med 48: 339-341, 2009.

11. Maioi M, Toso A, Leoncini $M$, et al. Sodium bicarbonate versus saline for the prevention of contrast-induced nephropathy in patients with renal dysfunction undergoing coronary angiography or intervention. J Am Coll Cardiol 52: 599-604, 2008.

(C) 2010 The Japanese Society of Internal Medicine http://www.naika.or.jp/imindex.html 